\title{
FISSURAS EM EDIFICAÇÕES PÚBLICAS ANTIGAS NA CIDADE DE FORTALEZA-CE: EXAME DAS CAUSAS E SOLUÇÕES
}

\author{
FERREIRA GOMES, JULIO ROBERTO \\ Graduando em Engenharia Civil \\ Centro Universitário Christus - UNICHRISTUS \\ Ceará; Brasil \\ juliorfgomes@outlook.com
}

\author{
DE OLIVEIRA QUESADO FILHO, NELSON \\ Mestre, Engenheiro Civil \\ Centro Universitário Christus - UNICHRISTUS \\ Ceará; Brasil \\ nquesado@gmail.com
}

\section{RESUMO}

Deve-se ter considerável atenção no que se concerne ao surgimento de patologias nas construções, sendo a mais comum a fissura, que é a menos grave, podendo se agravar nos estados de trinca até rachadura, ocorrendo de, nesses últimos casos, ser necessário interferência técnica, a exemplo do reforço estrutural ou, até mesmo, a demolição. Assim, faz-se necessário o mapeamento acerca dos tipos, formatos e profundidades das fissuras nas edificações antigas em decorrência destas já terem passado considerável tempo de vida útil de projeto. Em vista disso, o exame desse trabalho almeja ajudar aos projetistas futuros caso seja necessário requalificar essas construções antigas. O estudo será baseado na inspeção visual de edificações antigas na região central e litorânea de Fortaleza-CE, e, mediante essa análise, haverá a realização de um mapeamento dessas construções com suas características principais, a exemplo do tipo predominante de fissura.

Palavras-chave: edificação pública, fissura, patologia.

\section{ABSTRACT}

Considerable attention should be given to the emergence of pathologies in buildings, the most common being the thin crack, which is the least severe, and may worsen in the states of medium crack until wide crack, occurring, in the latter cases, technical interference, as structural reinforcement or even demolition. Thus, it is necessary to map the types, shapes and depths of cracks in old buildings because they have already passed considerable project lifetime. In view of this, the examination of this work aims to help future designers when it is necessary to requalify these old buildings. The study will be based on the visual inspection of old buildings in the central and coastal region of Fortaleza-CE, and, through this analysis, a mapping of these buildings with their main characteristics will be performed, such as the predominant type of thin crack.

Keywords: public building, thin crack, pathology.

\section{INTRODUÇÃO}

Os mecanismos de deterioração, de surgimento de falhas, bem como as causas, os efeitos e os tipos de patologias que podem ser ocasionadas nas estruturas das construções são estudados pelo ramo da engenharia civil chamado de patologia das estruturas (SOUZA \& RIPPER, 1998). Essa área de pesquisa é importante em decorrência de atuar na prevenção de desastres.

As trincas e as fissuras são os problemas mais comuns nas construções, seja residênciais ou comerciais, bem como, para o conhecimento adequado das suas causas, são necessários estudos de engenheiros qualificados, os quais devem avaliar de forma detalhada em decorrência da inconstância dos fatores ocasionadores dessas patologias. Ademais, a presença das fissuras e trincas nas construções proporcionam gastos econômicos consideráveis caso não sejam tratadas rapidamente, bem como as mesmas produzem insegurança aos usuários como consequência das características que têm quando começam a surgir. (MOLIN, 1988). Assim, são necessárias manutenções nas edificações que a apresentam, especialmente as edificações mais antigas, pois, por terem sido submetidas a mais tempo a ataques de agentes químicos, por exemplo, indica que as mesmas são mais frágeis quando apresentam esses tipos de patologia. 
Dessa forma, este estudo tem, como objetivo, apresentar os tipos de patologia mais comuns em edificações públicas antigas da cidade de Fortaleza-CE visando ao conhecimento do setor da construção civil no que se concerne à presença, principalmente, de fissuras, trincas e rachaduras nessas construções. Foi realizada análises visuais em campo nessas edificações, objetivando mapear essas anomalias para ser verificada as possiveis causas e consequências das mesmas. As edificações públicas examinadas foram: a) Centro Cultural Banco do Nordeste Fortaleza; b) Parque da Liberdade Fortaleza; c) Theatro José de Alencar; d) Centro Dragão do Mar de Arte e Cultura.

\section{REFERENCIAL TEÓRICO}

Quando a fissura presente da edificação permite a passagem de água, ou quando elas podem ser examinadas sem o auxílio de instrumentos ópticos em distâncias acima de 1 metro, significa que a mesma pode provocar outros tipos de anomalias nas construções (CEOTTO et al, 2005). Em vista disso, quando observar-se a presença dessas características devem ser tomadas decisões momentaneamente com intuito de impedir o surgimento de novas patologias decorrentes de uma patologia inicial, pois, no começo, o gasto é menor, e a solução menos complexa.

Quando o fator da causa da fissura for o recalque diferencial, deve-se ter atenção redobrada como resultado de esse tipo de recalque ser ocasionado pela fundação, que é um elemento estrutural extremamente importante por receber as cargas de toda a estrutura da edificação, sendo essencial para a segurança do habitante da construção. Portanto, caso haja o avanço desse tipo de fissura, deve-se procurar averiguar instantâneamente os problemas da fundação, que, certamente, é grave, e, com isso, evitar o risco de acidentes (MARCELLI, 2007). Quando a fissura atingir aspectos estruturais, deve ser analisado todas as possíveis causas, desde o projeto até a execução da construção e de serviços de reforma e manutenção, porque o risco atinge outro patamar.

As fissuras são ocasionadas por movimentações diferenciais, sendo que as principais são: a) as originadas por junção de materiais com solicitações térmicas diversas; b) as causadas por diferença de temperatura de um mesmo material, como a laje, em que uma parte tem maior calor por está em contato direto com a radiação solar em relação à outra que não está recebendo calor do sol; c) as derivadas de encontro de materiais com dilatações térmicas distintas (VALLE, 2008). O conhecimento das movimentações no processo de formação dessas anomalias são necessários para a averiguação da melhor forma de tratamento.

As reações químicas podem gerar fissuras, sendo a mais comum a fissura horizontal, resultante do avolumamento da argamassa, mais, especificamente, nas juntas. Ademais, esse avolumamento ocorre, principalmente, como resultado da reação de sulfatos com o cimento da argamassa, como também em decorrência da cal, caso exista o retardamento da hidratação deste último (MAGALHÃES, 2004). Além disso, as fissuras produzidas mediante reações químicas são intensificadas em ambientes com elevado teor de poluentes (RICHTER, 2007). A avaliação do local onde a construção está inserida é determinante para a prevenção no surgimento de patologias mediante a escolha do tratamento de acordo com o meio, pois a escolha de tratamentos em desarcordo com o ambiente poderá proporcionar maiores gastos futuros em decorrência da não durabilidade da intervenção para o não surgimento futuro de anomalias.

Tensões consideráveis no concreto podem surgir em decorrência do surgimento de óxido expansivo, pois estes aumentam consideravelemente o tamanho, o que ocasiona no aparecimento de rupturas pela tração, formando, com isso, fissuras com o mesmo sentido da armadura longitudinal e transversal na estrutura. Esses óxidos são gerados pela penetração da água na estrutura, que promove a corrosão (FERNÁNDEZ, 1988). O entendimento acerca da presença da água no ambiente é importante no que se concerne à corrosão, principalmente em ambientes litorâneos, que apresentam sais dissolvidos na umidade do ar.

A retração pode ser causador de fissuras, sendo que é a na alvenaria, isto é, a retração que ocorre em elementos estruturais, em blocos e em argamassa com função de junta, que possuem cimento como componente de produção, ocasionam no aparecimento de fissuras em alvenaria, e, com isso, em paredes (THOMAZ, 1989).

As trincas, as fissuras e outras patologias semelhantes podem ser preenchidas mediante a inserção de resina epóxi expansiva ou de graute, que são tipos de tratamento dessas patologias para a recuperação estrutural e estética. Destacase que o graute é aplicado nas rupturas mais largas, enquanto a resina epóxi é empregada nas rupturas mais estreitas, isto é, com menos de 2 milímetros (ELGAWADY, LESTUZZI \& BADOUX, 2004). A escolha do tipo ideal de intervenção para a durabilidade da construção tem relação com a largura da abertura, pois o mesmo pode indicar, ou não, se a anomalia está avançada ou não. 


\section{MATERIAIS E MÉTODOS}

Para um entendimento consistente acerca dos resultados dessa pesquisa, torna-se necessária a apresentação de conceitos importantes no que se refere às patologias em estudo, que são: a) definição do que seja fissuras, trincas e rachaduras; b) classificação das fissuras, trincas e rachaduras quanto à espessura da largura; c) classificação das fissuras quanto à atividade. Logo depois, é descrito como foi realizado o levantamento das patologias.

\subsection{Definição de fissura, trinca e rachadura}

As fissuras, as trincas e as rachaduras são aberturas decorrentes da solicitação superior ao limite de resistência em materiais, principalmente aos frágeis ao esforço de tração, a exemplo do concreto. Esses tipos de patologia na construção podem ser classificados de acordo com a espessura da largura (BOLINA, TUTIKIAN \& HELENE, 2019).

\subsection{Classificação em fissura, trinca e rachadura}

A classificação das fissuras, trincas, rachaduras, fendas e brechas de acordo com o tamanho da espessura encontra-se na tabela abaixo.

Tabela 1 - Classificação das fissuras de acordo com a largura da abertura em $\mathrm{mm}$.

\begin{tabular}{|c|c|}
\hline Anomalias & Aberturas $(\mathbf{m m})$ \\
\hline Fissura & Até 0,5 \\
\hline Trinca & De 0,5 a 1,5 \\
\hline Rachadura & De 1,5 a 5,0 \\
\hline Fenda & De 5,0 a 10,0 \\
\hline Brecha & Acima de 10,0 \\
\hline
\end{tabular}

Fonte: Oliveira (2012)

\subsection{Classificação da fissura quanto à atividade}

A classificação da fissura quanto à atividade é: a) ativa, que é o tipo de fissura em que a largura varia de acordo com o fator ocasionador dessa patologia, isto é, a espessura pode aumentar ou diminuir, dependendo do fenômeno que faz essa patologia surgir, a exemplo de que a fissura de recalque diferencial muda de acordo com o quanto a fundação recalca, e de que a fissura originada por processo térmico muda de forma dependente de o quanto ocorre a variação de temperatura; b) passiva, que é a fissura que não altera a sua largura e tipo de acordo que a vida útil da construção passa (GOMIDE, FAGUNDES \& GULLO, 2014).

\subsection{Levantamento das patologias}

Ressalta-se que realizou-se a análise visual dos ambientes das edificações públicas, bem como o material usado para as fotografias das fissuras foi a câmara fotográfica de um celular Android. Nos locais de análise dessas patologias, realizou-se a estimativa do número de fissuras de acordo com o tipo e localização, a exemplo de ser no pilar ou parede. Logo após a inserção dos valores dessas fissuras em tabela, fez-se a análise da incidência do tipo de fissuras em relação ao valor total de fissuras na edificação. Por fim, produziu-se uma comparação entre as fissuras dessas edificações, destacando as causas que ocasionam a incidência dos resultados obtidos. Destaca-se que esses valores serão apresentados em tabelas para poder verificar de forma mais simples os resultados mais impactantes.

\section{RESULTADOS E DISCUSSÕES}

As edificações públicas avaliadas foram: a) Centro Cultural Banco do Nordeste Fortaleza; b) Parque da Liberdade Fortaleza; c) Theatro José de Alencar; d) Centro Dragão do Mar de Arte e Cultura. A seguir, tem-se a tabela de endereços dessas edificações públicas. 


\section{СВРAT 2020 \\ CONGRESSO BRASILEIRO DE PATOLOGIA DAS CONSTRUÇÕES \\ DE 15 A 17 DE ABRIL | FORTALEZA - CE

Tabela 2 - Endereço das edificações públicas examinadas.

\begin{tabular}{|c|c|}
\hline \multicolumn{2}{|c|}{ Endereços das Edificações Públicas } \\
\hline Edificação & Endereço \\
\hline Centro Cultural Banco do Nordeste Fortaleza & Rua Conde d'Eu, 560 - Centro, Fortaleza-CE, 60055-070 \\
\hline Parque da Liberdade Fortaleza & Rua Pedro I, s/n - Centro, Fortaleza-CE, 60035-100 \\
\hline Theatro José de Alencar & Rua Liberato Barroso, 525 - Centro, Fortaleza-CE, 60030-160 \\
\hline Centro Dragão do Mar de Arte e Cultura & Rua Dragão do Mar, 81 - Praia de Iracema, Fortaleza-CE, 60060-390 \\
\hline
\end{tabular}

Fonte: Próprio Autor (2020)

O mapa da localização dessas construções encontra-se abaixo.

Figura 1: Localização das construções mapeadas em Fortaleza-CE.

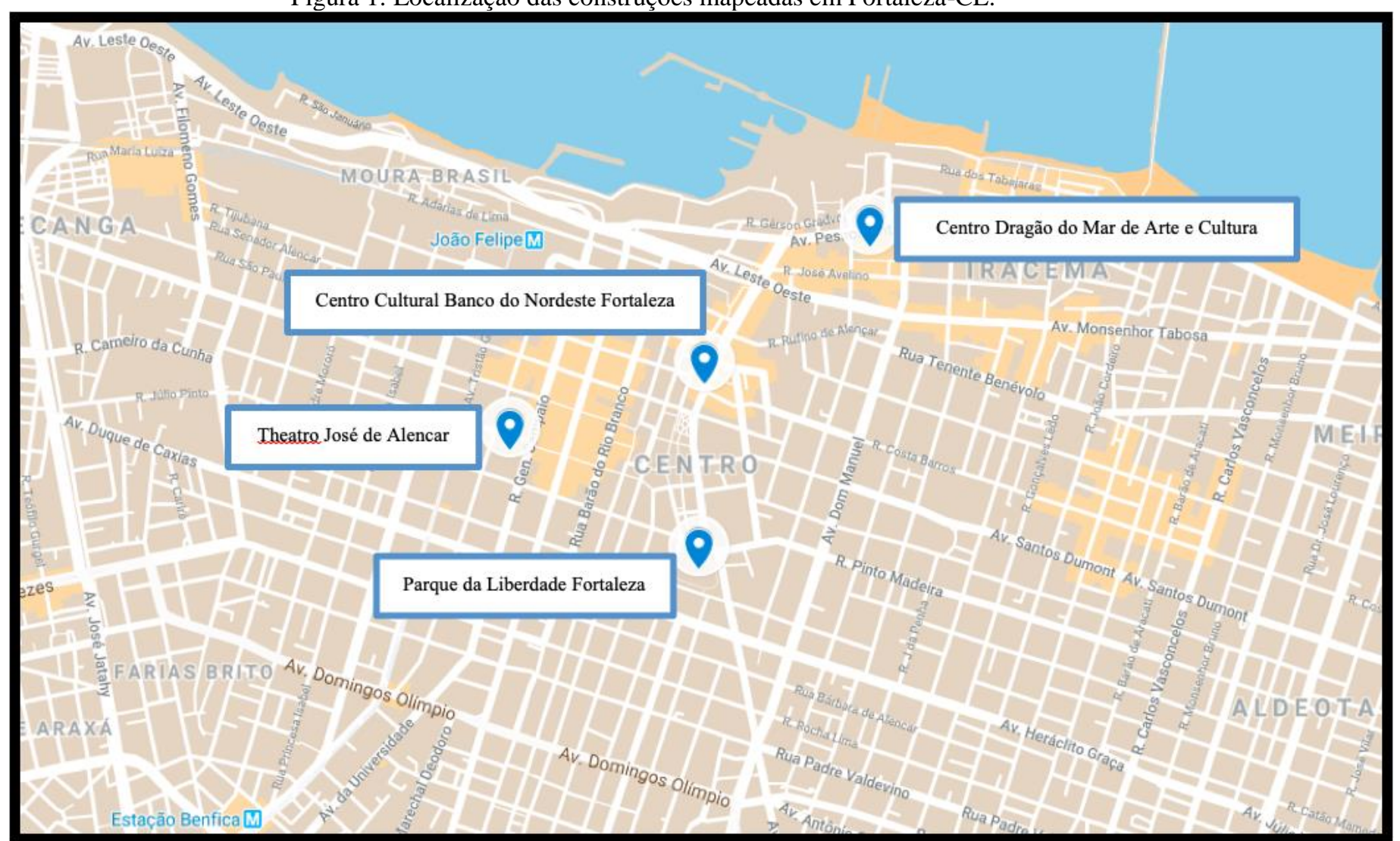

Fonte: Próprio Autor (2020)

A seguir, estão as fotografias relativas ao mapeamento das patologias no Centro Cultural Banco do Nordeste Fortaleza. 


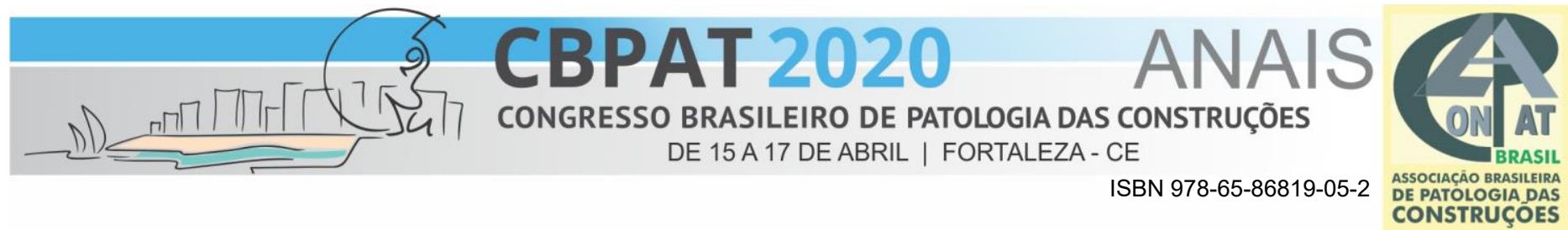

Figura 2: Patologias no Centro Cultural Banco do Nordeste Fortaleza

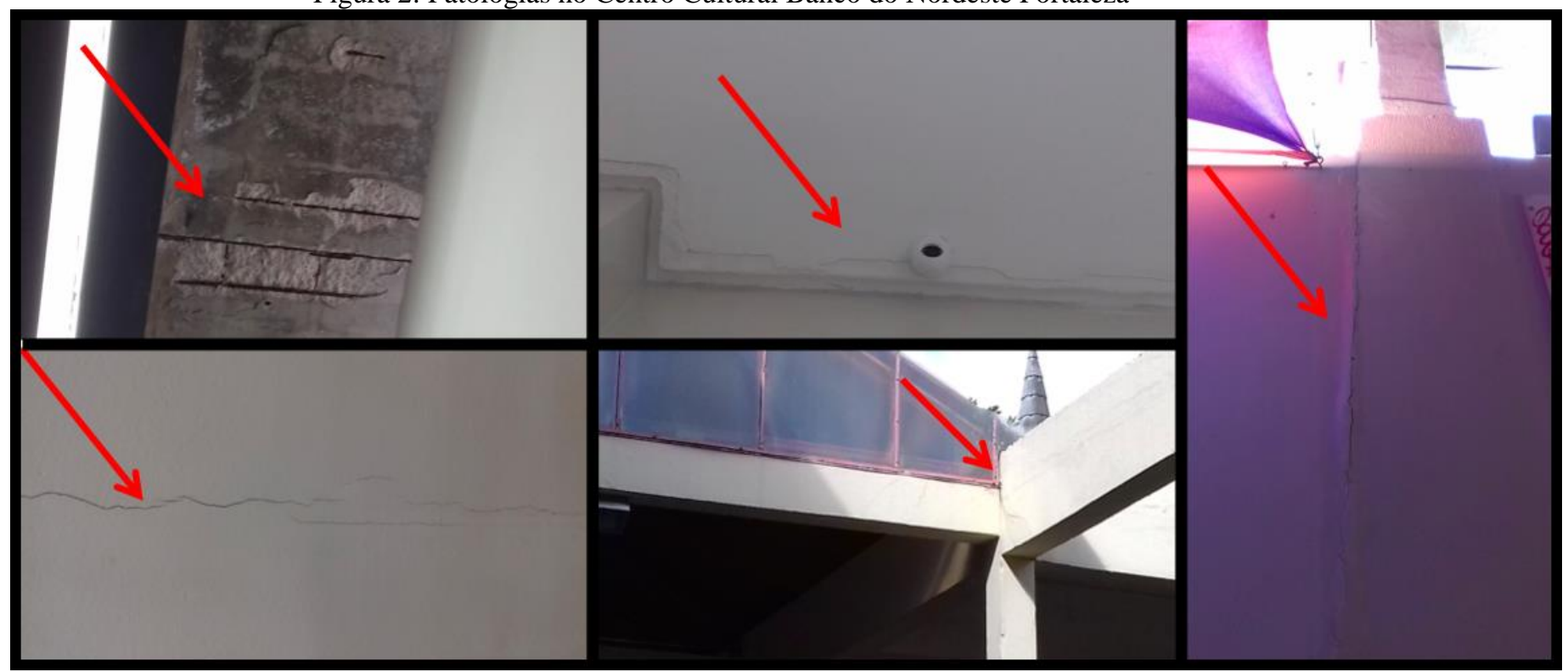

Fonte: Próprio Autor (2020)

A seguir, estão as fotografias relativas ao mapeamento das patologias no Parque da Liberdade Fortaleza.

Figura 3: Patologias no Parque da Liberdade Fortaleza.

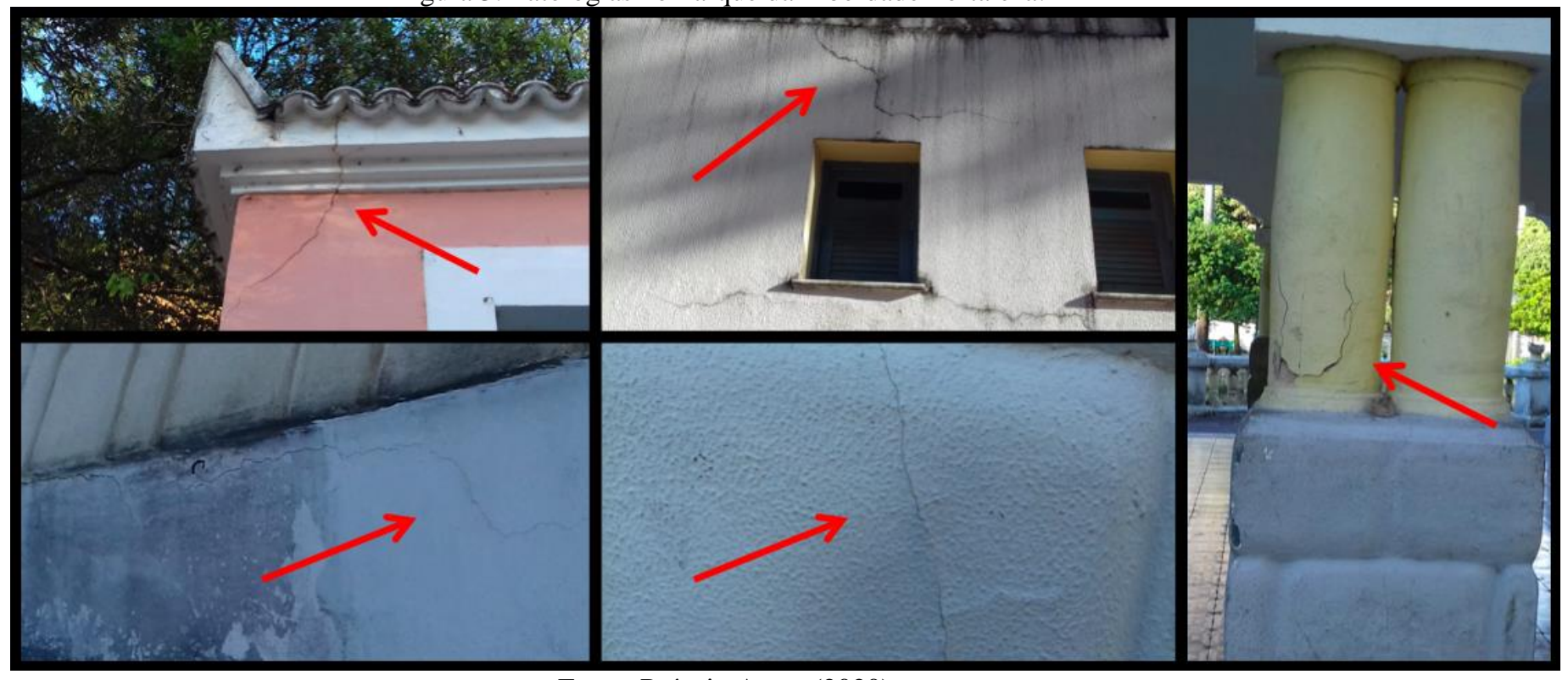

Fonte: Próprio Autor (2020)

A seguir, estão as fotografias relativas ao mapeamento das patologias no Theatro José de Alencar. 
Figura 4: Patologias no Theatro José de Alencar

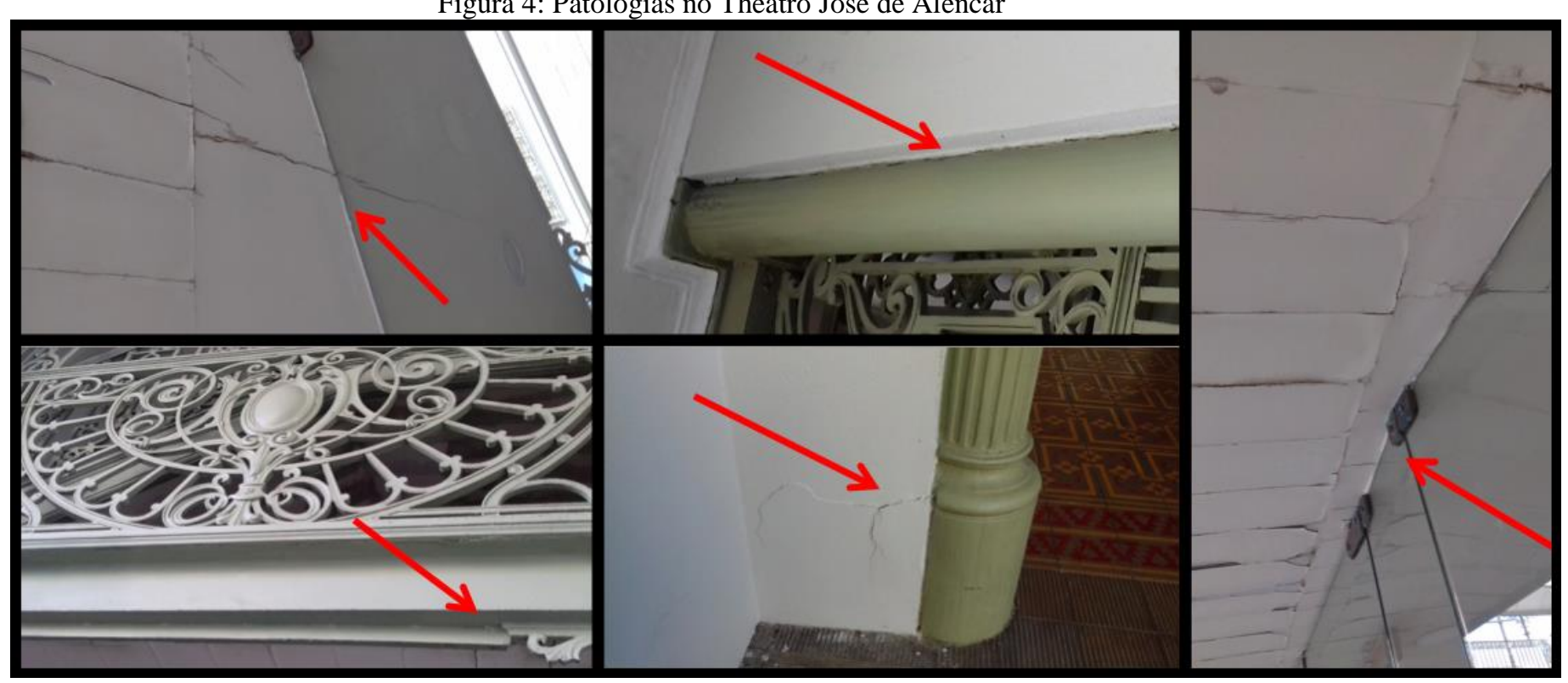

Fonte: Próprio Autor (2020)

A seguir, estão as fotografias relativas ao mapeamento das patologias no Centro Dragão do Mar de Arte e Cultura.

Figura 5: Patologias no Centro Dragão do Mar de Arte e Cultura.

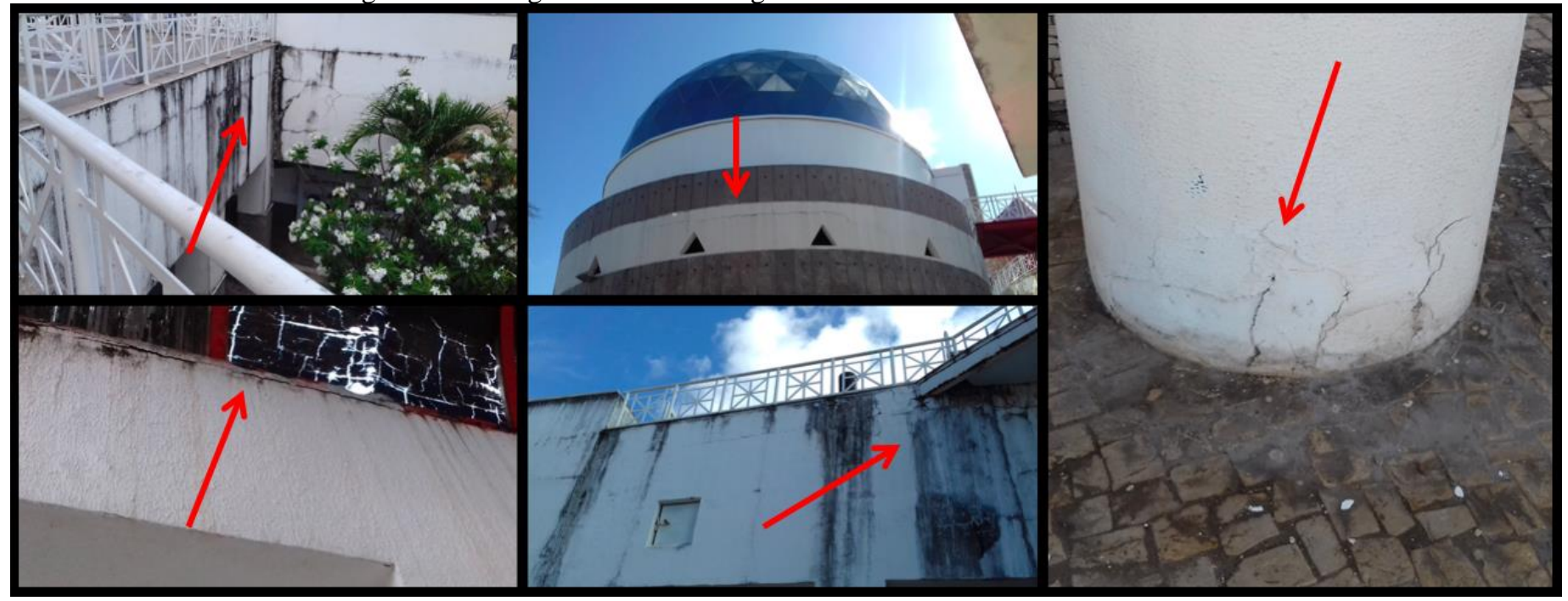

Fonte: Próprio Autor (2020)

A seguir, estão as tabelas relativas ao mapeamento das patologias no Centro Cultural Banco do Nordeste Fortaleza. 


\section{CBPAT 2020

Tabela 3 - Número de fissuras de acordo com o tipo no Centro Cultural Banco do Nordeste Fortaleza

\begin{tabular}{|c|c|c|}
\hline \multicolumn{2}{|c|}{ Edificação Pública 1 - Centro Cultural Banco do Nordeste Fortaleza } \\
\hline Tipo de Patologia & Quantidade & Porcentagem (\%) \\
\hline Fissura horizontal em parede & 1 & 2,2 \\
\hline Fissura vertical em pare de & 22 & 48,9 \\
\hline Fissura transversal em laje & 4 & 8,9 \\
\hline Fissura longitudinal em viga & 15 & 33,3 \\
\hline Fissura transversal em viga & 1 & 2,2 \\
\hline Fissura longitudinal em pilar & 1 & 2,2 \\
\hline Fissura transversal em escada & 1 & 2,2 \\
\hline Total de fissuras & 45 & 100,0 \\
\hline
\end{tabular}

Fonte: Próprio Autor (2020)

Tabela 4 - Número de outras patologias verificadas de acordo com o tipo no Centro Cultural Banco do Nordeste Fortaleza

\begin{tabular}{|c|c|}
\hline \multicolumn{2}{|c|}{ Edificação Pública 1 - Centro Cultural Banco do Nordeste Fortaleza } \\
\hline Tipo de Patologia & Quantidade \\
\hline Descascamento no pilar & 1 \\
\hline Armadura exposta em laje & 1 \\
\hline
\end{tabular}

Fonte: Próprio Autor (2020)

A seguir, estão as tabelas relativas ao mapeamento das patologias no Parque da Liberdade Fortaleza.

Tabela 5 - Número de fissuras de acordo com o tipo no Parque da Liberdade Fortaleza.

\begin{tabular}{|c|c|c|}
\hline \multicolumn{2}{|c|}{ Edificação Pública 2 - Parque da Liberdade Fortaleza } \\
\hline Tipo de Patologia & Quantidade & Porcentagem (\%) \\
\hline Fissura horizontal em parede & 13 & 41,9 \\
\hline Fissura vertical em parede & 10 & 32,3 \\
\hline Fissura diagonal em parede & 5 & 16,1 \\
\hline Fissura cruzada em parede & 2 & 6,5 \\
\hline Fissura longitudinal em pilar & 1 & 3,2 \\
\hline Total de fissuras & 31 & 100,0 \\
\hline
\end{tabular}

Fonte: Próprio Autor (2020)

Tabela 6 - Número de outras patologias verificadas de acordo com o tipo no Parque da Liberdade Fortaleza

\begin{tabular}{|c|c|}
\hline \multicolumn{2}{|c|}{ Edificação Pública 2 - Parque da Liberdade Fortaleza } \\
\hline Tipo de Patologia & Quantidade \\
\hline Trinca longitudinal no Pilar & 1 \\
\hline Descascamento em parede & 1 \\
\hline
\end{tabular}

Fonte: Próprio Autor (2020)

A seguir, estão as tabelas relativas ao mapeamento das patologias no Theatro José de Alencar. 
Tabela 7 - Número de fissuras de acordo com o tipo no Theatro José de Alencar.

\begin{tabular}{|c|c|c|}
\hline \multicolumn{2}{|c|}{ Edificação Pública 3 - Theatro José de Alencar } \\
\hline Tipo de Patologia & Quantidade & Porcentagem (\%) \\
\hline Fissura horizontal em pare de & 3 & 0,4 \\
\hline Fissura vertical em parede & 21 & 2,7 \\
\hline Fissura longitudinal em laje & 502 & 63,5 \\
\hline Fissura transversal em laje & 176 & 22,3 \\
\hline Fissura longitudinal em viga & 41 & 5,2 \\
\hline Fissura transversal em viga & 7 & 0,9 \\
\hline Fissura longitudinal em pilar & 6 & 0,8 \\
\hline Fissura transversal em pilar & 13 & 1,6 \\
\hline Fissura longitudinal em escada & 22 & 2,8 \\
\hline Total de fissuras & 791 & 100,0 \\
\hline
\end{tabular}

Fonte: Próprio Autor (2020)

Tabela 8 - Número de outras patologias verificadas de acordo com o tipo no Theatro José de Alencar.

\begin{tabular}{|c|c|}
\hline \multicolumn{2}{|c|}{ Edificação Pública 3 - Theatro José de Alencar } \\
\hline Tipo de Patologia & Quantidade \\
\hline Descascamento no pilar & 2 \\
\hline
\end{tabular}

Fonte: Próprio Autor (2020)

A seguir, estão as tabelas relativas ao mapeamento das patologias no Centro Dragão do Mar de Arte e Cultura.

Tabela 9 - Número de fissuras de acordo com o tipo no Centro Dragão do Mar de Arte e Cultura.

\begin{tabular}{|c|c|c|}
\hline \multicolumn{2}{|c|}{ Edificação Pública 4 - Centro Dragão do Mar de Arte e Cultura } \\
\hline Tipo de Patologia & Quantidade & Porcentagem (\%) \\
\hline Fissura horizontal em parede & 101 & 20,4 \\
\hline Fissura vertical em parede & 40 & 8,1 \\
\hline Fissura diagonal em parede & 34 & 6,9 \\
\hline Fissura cruzada em parede & 32 & 6,5 \\
\hline Fissura longitudinal em laje & 15 & 3,0 \\
\hline Fissura transversal em laje & 24 & 4,8 \\
\hline Fissura diagonal em laje & 1 & 0,2 \\
\hline Fissura cruzada em laje & 1 & 0,2 \\
\hline Fissura longitudinal em viga & 21 & 4,2 \\
\hline Fissura transversal em viga & 11 & 2,2 \\
\hline Fissura cruzada em viga & 3 & 0,6 \\
\hline Fissura longitudinal em pilar & 29 & 5,8 \\
\hline Fissura transversal em pilar & 145 & 29,2 \\
\hline Fissura diagonal em pilar & 1 & 0,2 \\
\hline Fissura cruzada em pilar & 35 & 7,1 \\
\hline Fissura longitudinal em escada & 1 & 0,2 \\
\hline Fissura transversal em escada & 2 & 0,4 \\
\hline Total de fissuras & 496 & 100,0 \\
\hline
\end{tabular}

Fonte: Próprio Autor (2020) 
Tabela 10 - Número de trincas de acordo com o tipo no Centro Dragão do Mar de Arte e Cultura.

\begin{tabular}{|c|c|c|}
\hline \multicolumn{2}{|c|}{ Edificação Pública 4 - Centro Dragão do Mar de Arte e Cultura } \\
\hline Tipo de Patologia & Quantidade & Porcentagem (\%) \\
\hline Trinca longitudinal em laje & 2 & 15,4 \\
\hline Trinca longitudinal em viga & 1 & 7,7 \\
\hline Trinca transversal em viga & 1 & 7,7 \\
\hline Trinca cruzada em viga & 1 & 7,7 \\
\hline Trinca longitudinal no pilar & 8 & 61,5 \\
\hline Total de Trincas & 13 & 100,0 \\
\hline
\end{tabular}

Fonte: Próprio Autor (2020)

Tabela 11 - Número de outras patologias verificadas de acordo com o tipo no Centro Dragão do Mar de Arte e Cultura.

\begin{tabular}{|c|c|}
\hline Edificação Pública 4 - Centro Cultural Dragão do Mar de Arte e Cultura \\
\hline Tipo de Patologia & Quantidade \\
\hline Descascamento no pilar & 2 \\
\hline Armadura exposta em laje & 1 \\
\hline
\end{tabular}

Fonte: Próprio Autor (2020)

Verificando os resultados obtidos na edificação pública 1, que é o Centro Cultural Banco do Nordeste Fortaleza, percebe-se que as fissuras predominantes são: a) fissura vertical em parede com 48,9\%; b) fissura longitudinal em viga com $33,3 \%$. Ademais, observa-se que a maioria das fissuras ocorrem em parede, que corresponde a um total de $51,1 \%$ de fissuras totais existentes na construção, enquanto a menor presença de fissuras ocorre em pilares e escadas. Destacase que, como são fissuras, as causas das mesmas podem ser decorrentes de falta de manutenção na parte do acabamento, mais especificamente na pintura das paredes. Na parte das vigas, uma das causas da presença considerável de fissuras possa ser a próximidade das mesmas com o ambiente externo da edificação, e, com isso, haver maior possibilidade do maior contato com a água. Bem como, na parte das outras patologias, a causa principal para o descascamento e a exposição da armadura possa ser o contato com a água. Dessa forma, possíveis soluções para amenizar essas problemáticas seriam: a) manutenção do acabamento com forma adequada da realização da pintura, principalmente com a execução adequada do descascamento da pintura antiga; b) adequação de elementos protetores contra a incidência de água, a exemplo da ampliação da coberta, ou o encontro e solução de possíveis problemas na coberta, como a ocorrência de goteiras; c) realização do reboco e acabamento de pintura, ou, até mesmo, reforço estrutural nas situações em que se verifique a redução da bitola de aço, bem como a procura e a solução de possíveis ocasionadores da entrada da água que provoque buracos, descascamentos, e, consequentemente, a exposisão dessa armadura ao ambiente.

Em relação ao Parque da Liberdade Fortaleza, observa-se que as fissuras predominantes são: a) fissura horizontal em parede com 41,9\%; b) fissura vertical em parede com 32,3\%. Como também, verifica-se que a maioria das fissuras ocorrem em parede, que corresponde a um total de $96,8 \%$ de fissuras totais existentes na construção, e a menor quantidade de fissura ocorre em pilar. Salienta-se a existência da trinca em pilar. Destaca-se que, em decorrência de serem fissuras nas paredes, as causas das mesmas podem ser decorrentes de falta de manutenção na parte do acabamento, isto é, na realização da pintura das paredes. Além disso, na parte das outras patologias, uma das causas possíveis para a presença de trinca longitudinal no pilar seja o ataque de agentes químicos ou realização de projeto inadequado no que se concerne ao dimensionamento da estrutura em forma que não dimensione, somente, referente ao suporte das cargas em que a estutura será submetida, mas, também, que a estrutura não apresente patologias que causam desconforto visual ao usuário. No que se refere à presença de descascamento em parede, uma das possíveis causas possa ser infiltrações. Portanto, possíveis soluções para essas patologias seriam: a) manutenção do acabamento com forma adequada da realização da pintura, principalmente com a execução adequada do descascamento da pintura antiga; b) adequação de elementos protetores contra a incidência de água, a exemplo da ampliação da coberta, ou o encontro e solução de possíveis problemas na coberta, como a ocorrência de goteiras; c) realização do reboco e acabamento de pintura; d) resolução de causadores da entrada da água que provoque descascamentos; d) tratamento da trinca mediante a injeção de graute ou resina epóxi expansiva.

Analisando os valores observados no Theatro José de Alencar, constata-se que as fissuras preponderantes são: a) fissura longitudinal em laje, correspondente a $63,5 \%$; b) fissura transversal em laje com 22,3\%. Bem como, ressalta-se-se que a maioria das fissuras ocorrem em laje, que equivale a $85,8 \%$ do valor total. A menor aparição de fissuras ocorre em 
paredes e pilares. Salienta-se que, como são fissuras em laje, os motivos das mesmas surgirem podem ter, como consequência, a falta de manutenção na parte do acabamento, ou, mesmo, realização inadequada do mesmo, pois as mesmas encontram-se distribuídas de forma conjunta. Enfatiza-se a pouca quantidade de fissuras nas paredes, que é o tipo de patologia mais comum nas outras edificações analisadas, indicando a realização adequada da pintura nas paredes. Além disso, no que se concerne às outras patologias, o principal motivo para o descascamento no pilar possa ser a penetração da água. Em vista disso, soluções que podem ser aplicadas para o tratamento dessas anomalias seriam: a) manutenção do acabamento da laje com forma adequada da realização da pintura, principalmente com a execução adequada do descascamento da pintura antiga; b) adequação de elementos protetores contra a incidência de água, a exemplo da ampliação da coberta, ou o encontro e solução de possíveis problemas na coberta, como a ocorrência de goteiras; c) tratamento do descascamento presente no pilar por meio da aplicação de graute ou resina epóxi expansiva.

No que se concerne ao Centro Dragão do Mar de Arte e Cultura, verifica-se que as fissuras predominantes são: a) fissura transversal em pilar com 29,2\%; b) fissura horizontal em parede com 20,4\%. Assim como, constata-se que a maior quantidade das fissuras que aparecem manifestam-se em pilares, que correspondem a um total de $42,3 \%$ das fissuras existentes, e as fissuras são menos presentes nas escadas com 0,6\%. Ressalta-se a presença considerável de fissuras nas paredes, que é de 41,7\%, apontando para a dedução da presença comum das fissuras em paredes nas edificações. Destaca-se que, por serem fissuras, as possíveis causas são consequência de falta de manutenção na parte do acabamento, isto é, na realização da pintura das paredes e pilares, entretanto, como verificou-se presença considerável de fissuras transversais no pilar e de presença maior de formatos de fissuras, como a diagonal, outras causas possíveis para isso sejam o dimensionamento inapropriado do pilar em relação à função estética, o maior contato dos pilares com a água como resultado desses estarem presentes em ambiente parcialmente abertos e o ataque de agentes químicos em decorrência da proximidade ao mar, que proporciona o surgimento mais variado da fissuração. Além disso, na parte das outras patologias, uma das causas possíveis para a presença de trincas nas lajes, vigas e lajes seja o contato com sais da maresia em decorrência da distância curta ao litoral, ou realização de projeto inadequado no que se concerne ao dimensionamento da estrutura em forma que dimensione, somente, referente ao suporte das cargas em que a estutura será submetida sem que haja considerações em relação às patologias que causam desconforto visual ao usuário. Portanto, possíveis soluções para essas patologias seriam: a) manutenção do acabamento com forma adequada da realização da pintura, principalmente com a execução adequada do descascamento da pintura antiga; b) adequação de elementos protetores contra a incidência de água, a exemplo da ampliação da coberta, ou o encontro e solução de possíveis problemas na coberta, como a ocorrência de goteiras; c) utilização de técnicas especiais no combate ao ataques de sais, a exemplo de pinturas especiais; d) tratamento do descascamento presente no pilar por meio da aplicação de graute ou resina epóxi expansiva; e) tratamento das trinca mediante a injeção de graute ou resina epóxi expansiva.

\section{CONCLUSÃO}

Pode-se observar nessa pesquisa que: a) as fissuras mais comuns são as presentes em paredes; b) a realização adequada dos processos de acabamento de uma edificação são relevantes para as presenças futuras da maioria das patologias, especialmente fissuras; c) o tipo de patologia predominante é a fissura; d) a distância da construção em relação ao mar tem influência na presença considerável das anomalias; e) para uma durabilidade maior do tratamento aplicado nas patologias, é necessário o conhecimento acerca de todas as causas, criteriosamente, no que se refere à formação das patologias; e) quanto mais rápida for aplicada a intervenção no combate a esses tipos de malefícios, menos será o gasto.

Dessa forma, como os edíficios mais antigos já têm passado considerável tempo de vida útil, é necessária atenção redobrada no que se concerne às patologias, mais especificamente às causas. Portanto, são essenciais pesquisas referentes às origens e soluções mais adequadas para cada tipo de patologia, principalmente de fissuras, porque é a mais comum, enfatizando-se em edificações mais antigas.

\section{REFERÊNCIAS}

BOlinA, F. L.; TUtiKiAn, B. F.; HELENE, P. R. L. Patologia de estruturas. 1. São Paulo: Oficina de Textos, 2019.

CEOTTO, L. H.; BANDUK, R. C.; NAKAKURA, E. H. Revestimentos de Argamassas: boas práticas em projeto, execução e avaliação. 1. Porto Alegre: Prolivros, 2005. 
ELGAWADY, M.; LESTUZZI, P.; BADOUX, M. A review of convencional seismic retrofitting techiniques for URM. In: INTERNATIONAL BRICK AND BLOCK MASONRY, 13, 2004, Amsterdam. Quadrienais... Amsterdam: [s.n.], 2004.

FERNANDÉZ, C. M. Patologia e terapia do concreto armado. 1. São Paulo: Pini, 1988.

GOMIDE, T. L. F.; FAGUNDES, J. C. P.; GULLO, M. A. Engenharia diagnóstica em edificações. 2. São Paulo: Pini, 2014.

MAGALHÃES, E. F. Fissuras em alvenarias: configurações típicas e levantamento de incidências no Estado do Rio Grande do Sul. 2004. 180 f. Trabalho de Conclusão (Mestre em Engenharia) - Universidade Federal do Rio Grande do Sul, Porto Alegre, 2004.

MARCELLI, M. Sinistros na Construção Civil. 1. São Paulo: Pini, 2007.

MOLIN, D. C. C. V. Fissuras em estruturas de concreto armado: análise das manifestações típicas e levantamento de caso ocorrido no estado do Rio Grande do Sul. 1988. 238 f. Dissertação (Mestre em Engenharia) - Universidade Federal do Rio Grande do Sul, Porto Alegre, 1988.

OLIVEIRA, A. M. Fissuras e rachaduras causadas por recalque diferencial de fundações. $2012.96 \mathrm{f}$. Monografia (Especialização em Gestão em Avaliações e Perícias) - Universidade Federal de Minas Gerais, Belo Horizonte, 2012.

RICHTER, C. Qualidade da alvenaria estrutural em habitações de baixa renda: uma análise de confiabilidade e da conformidade. 2007. 180 f. Dissertação (Mestre em Engenharia) - Universidade Federal do Rio Grande do Sul, Porto Alegre, 2007.

SOUZA, V. C. M.; RIPPER, T. Patologia, recuperação e reforço de estruturas de concreto. 1. São Paulo: Pini, 1998.

THOMAZ, E. Trincas em edifícios: causas, prevenção e recuperação. 1. São Paulo: Pini, 1989.

VALLE, J. B. S. Patologia das alvenarias. 2008. 81 f. Monografia (Especialização em Tecnologia da Construção Civil) - Departamento de Engenharia de Materiais e Construção, Universidade Federal de Minas Gerais, Belo Horizonte, 2008. 